\title{
Los servicios sanitarios públicos: escenario de una subversión cotidiana de la política heterosexual
}

\author{
Public bathrooms: Scenario of a daily subversion \\ of heterosexual politics \\ Marcela Otárola Guevara \\ Escuela de Historia, Universidad Nacional, Costa Rica \\ zaida.otarola.guevara@una.cr
}

Recibido: 21/01/2019 • Aceptado: 16/10/2019

\section{RESUMEN}

Los servicios sanitarios, lugares cotidianos e indispensables, son el escenario de una práctica homosexual, denominada cruising, que desafía la política heterosexual materializada en normas que regulan la edificación y legitiman, simultáneamente, la construcción binaria del género asociada a la genitalidad. Como resultado de un seminario doctoral, en el presente ensayo se muestran los resultados de una investigación que recoge las principales directrices nomotéticas costarricenses que tutelan el diseño y levantamiento de los baños. Asimismo, se acopian testimonios de hombres quienes, de cara a la praxis y retórica heteronormativa, se apropian de estos espacios para subvertir su connotación y, así, desmantelar su función como deponente del género.

Palabras clave: Espacios homoeróticos, arquitectura del poder, cancaneo homosexual, segregación sexual 


\begin{abstract}
The water closets, daily and indispensable places, are the scene of a homosexual practice called cruising that challenges the heterosexual policy materialized in rules that regulate the building and legitimize, simultaneously, the binary construction of the genre associated with genitality. As a result of a doctoral seminar, the present essay shows the results of an investigation that includes the main nomothetic Costa Rican guidelines that protect the design and construction of bathrooms. Likewise, testimonies of men are collected, and they, in order to face the heteronormative praxis and rhetoric, proceed to appropriate these spaces to subvert their connotation and, thus, dismantle their function as a deponent of the genre.
\end{abstract}

Keywords: Homoerotic spaces, architecture of power, homosexual cancaneo, sexual segregation

\title{
UNA APROXIMACIÓN AL USO DEL ESPACIO COMO MECANISMO DE ALIENACIÓN
}

A continuación, se realiza una reflexión sobre apropiaciones antagónicas del espacio que se desprenden de una pugna por fijar el género desde una perspectiva heterosexual. En esta disputa, se destaca el uso instrumental de la arquitectura como medio para disciplinar actos y construir subjetividades, pues ha jugado un papel importante al incorporar, a través de la legislación constructiva, una norma que determina lo femenino y lo masculino en espacios de uso indispensable: los servicios sanitarios. Sin embargo, en oposición a esta normativa, prácticas sexuales como el cruising han procedido a resignificar estos espacios y trastocan el sentido heteronormado concedido a los baños públicos: estas locaciones dejan de ser herramienta para fomentar el binarismo que instaura roles de género y se tornan en espacios para intimar entre personas del mismo sexo.

La denuncia de un hecho que ofende a minorías sexuales condujo a preguntar: ¿de qué modo se expresa el poder como noción relacional en espacios de uso público?, cuestionamiento que constituyó el punto de partida para realizar una descripción de las fuerzas agonistas que actúan en él y que se materializan en alocuciones y actos. De esta manera, inicialmente se presenta un recuento de discursos que señalan al servicio sanitario 
como un mecanismo de control y, a la vez, como espacio para alcanzar la socialización y liberación gay a través de acciones homoeróticas. Interesa enfocarse en este último aspecto, porque refleja una praxis devenida de una subjetivación homosexual que es discordante y provocadora, lo cual la constituye parte de un proceso de autonomía política.

Es importante mencionar que este ensayo es sobre el poder y, por ello, su objetivo es introducir una deliberación teórica, sustentada en aportes de filósofos y estudiosos del género, sobre las distintas relaciones de dominio que se expresan en la toma espacial de lugares cotidianos. Para iniciarla, se conformó un acervo con información procedente de distintas fuentes documentales, tales como reglamentos y códigos constructivos de consulta obligatoria que regulan el diseño de los servicios sanitarios, mientras que, para conocer sobre el cruising, se visitaron los dos sitios web más visibles en Internet donde se describen los lugares frecuentados para estos encuentros, y un foro donde los interlocutores relatan su experiencia en el ejercicio de esa actividad. Posteriormente, se procedió a analizar los textos recopilados según referencias teóricas y, finalmente, se preparó una consideración final.

\section{MÁS QUE UN RÓTULO EN LA PUERTA DEL BAÑO}

En el año 2016, una hoja impresa, escrita en computadora, colocada en la puerta de un servicio sanitario junto a un rótulo de "DAMAS" y a otro con un ícono alusivo a dicho término, enunciaba lo siguiente: "Servicio sanitario solo para mujeres. Estas son las que nacieron con vagina. Los hombres y los playos usen el otro sanitario". Un joven gay que visitó el lugar, un local de la Cadena de Detallistas Heredianos, fotografió la imagen y la publicó en Facebook, lo que causó molestia e indignación, particularmente en la población transexual.

Luego, un vocero de la empresa ofreció disculpas e indicó que, para corregir el error, buscarían asesoría para sensibilizarse ante las "distintas necesidades de los demás" (Alvarado, 2016, parr. 6). Con la declaración de enmienda de la organización finalizó la cobertura periodística del incidente, pero elucidó el anclaje de heteronormatividad en las actividades cotidianas del ser humano. Ello propicia la reflexión sobre el uso del espacio arquitectónico como palestra para el funcionamiento de mecanismos que fijan identidades de género según los genitales del individuo. 
El uso disciplinar de espacios sanitarios no es nuevo; ha sido abordado por investigadores sociales y, uno de ellos es Georges Vigarello quien, al referirse a la ablución como un ejercicio de dominación perpetrado por grupos hegemónicos en el siglo XIX, analizó la edificación de baños y determinó que estos han sido parte de un proceso pedagógico pues, en la población, instauran pautas que se tienden a generalizar de forma irreflexiva (1991, p. 273). Los servicios sanitarios son una muestra de este acto y, para Paul Beatriz Preciado (s.f.), tal estrategia surge cuando instituciones europeas burguesas, al seguir códigos conyugales y domésticos decimonónicos, instituyen los baños públicos como medio para la definición espacial de los géneros con el fin de "normalizar la heterosexualidad y patologizar la homosexualidad", situación que prosigue en las décadas siguientes:

En el siglo XX, lo retretes se vuelven auténticas células públicas de inspección en las que se evalúa la adecuación de cada cuerpo con los códigos vigentes de la masculinidad y feminidad. En la puerta de cada retrete, como único signo, una interpelación de género: masculino o femenino, damas o caballeros, sombrero o palmera, bigote o florecilla, como si hubiera que entrar al baño a rehacerse del género más que a deshacerse de la orina y de la mierda (p.1).

En la cita anterior, Preciado expresa que la arquitectura funciona como una "prótesis de género" (p. 3) y, así, involucra al diseño del entorno en una naturalización del sexo y del género. La prótesis constituye un dispositivo artificial que emula a un miembro natural ausente del cuerpo y pretende hacerlo sentir congénito; en este sentido, la arquitectura, a través de la disposición espacial, instaura el sexo y el género según las funciones biológicas humanas; de este modo, prescinde de otras posibles formas identitarias del individuo.

El binarismo hombre/mujer ratificado en la iconografía que señalizan los baños, es la expresión última de una norma heterosexual que, reiteradamente, se advierte en los estatutos reguladores de la construcción edilicia en Costa Rica. Por ejemplo, en el Código de Instalaciones Hidráulicas y Sanitarias en Edificaciones (2017) elaborado por el Colegio Federado de Ingenieros y Arquitectos (CFIA), se establece que centros de salud, cárceles, oficentros, locales comerciales e industriales, instalaciones deportivas, centros educativos y restaurantes, por citar unos casos, deberán 
contar con servicios sanitarios separados para hombres y mujeres cuando se congreguen grupos de usuarios mayores a 10 o 15 personas (el número varía según el tipo de inmueble).

De forma similar, el Reglamento de Construcciones del Instituto Nacional de Vivienda y Urbanismo (INVU) ratifica la directriz en varios de sus artículos, al afirmar que los servicios sanitarios públicos deberán separarse "por sexo", e incluso detalla que, si están contiguos, deberán ser diseñados "de forma tal que permitan una adecuada independencia" (1982, art. VIII.8.1), lo cual sugiere el levantamiento de barreras físicas para acentuar la diferencia hombre/mujer en función del dualismo pene/vagina.

Si se considera que este marco normativo es de acatamiento ineludible para la construcción de espacios donde permanece el sujeto gran parte de su vida (centros de estudio, el trabajo, lugares de consumo o sitios lúdicos), que define los criterios de diseño para recintos imprescindibles en las actividades diarias, pues atienden necesidades fisiológicas impostergables -como lo son la micción y la defecación- y, además, establece en ellos el empleo de recursos materiales legitimadores de roles patriarcales de género, tales como los mingitorios que permiten al hombre orinar de pie y en público, en tanto que las mujeres lo hacen sentadas y en privado porque disponen para ello de inodoros dentro de cubículos, se deduce que los baños constituyen una "prótesis de género" efectiva porque regulariza, mediante la apropiación espacial cotidiana y utilitaria, una determinación del género según la genitalidad. Es importante mencionar que, si bien los reglamentos permiten el uso de servicios sanitarios unisex, estos son habilitados para inmuebles pequeños y con pocos usuarios, razón por la cual no son comunes en los espacios públicos. Asimismo, interesa continuar con el abordaje de los servicios sanitarios públicos de uso habitual pues, a pesar de la normalización sexual a la que han estado expuestos, ellos también son escenario de prácticas que la subvierten, como el cruising o cancaneo gay, las que son llevadas a cabo por sujetos disidentes que se resisten a la imposición del canon buga (palabra última que, en el argot homosexual, alude a la heterosexualidad).

\section{EL PLACER TRAS LA PUERTA DEL BAÑO}

El cancaneo es el encuentro sexual, anónimo y ocasional, que ocurre en zonas de acceso al público. Cuando lo practica una pareja 
heterosexual se denomina dogging, mientras que el cruising refiere al acto entre dos hombres llamados comúnmente cruiser quienes, en la jerga científica, se suelen identifican mediante el epígrafe HSM (hombres que tienen sexo con hombres) pues no es una práctica exclusiva de gais (Grau-Munoz et al., 2015).

El cruising se desarrolla en lugares -tanto abiertos como cerrados- diseñados para usos específicos que cuentan con un significado establecido y compartido por la mayoría de las personas; entonces, se suele realizar en un parque destinado a la recreación familiar, en una cancha que posibilita la actividad deportiva colectiva o un en baño público que se construye para excretar u orinar, ninguno de ellos dispuesto para el encuentro sexual; es esta condición, lo que no está dispuesto para otros, lo que motiva al cruiser a ocupar tales sitios (Rojas, 2016).

Los espacios para llevar a cabo el cancaneo gay pueden ser ubicados mediante aplicaciones que se instalan en dispositivos móviles como la denominada Cruising, en tanto que otros son divulgados en Internet a través de páginas web donde se agrega, además de su localización, algunas características físicas, horarios convenientes, el tipo de cruiser que los frecuenta y la forma de contactarlo personalmente. Así, a través de sitios web como www.cruisinggays.com y www.gays-cruising.com, en Costa Rica, se pueden identificar los sitios recomendados para esta actividad.

En www.cruisinggays.com hacen un recuento de 42 lugares en el territorio nacional y destacan los 20 más populares, todos ubicados en la Gran Área Metropolitana. De ellos, cinco son locales privados (spas, discotecas o bares), seis son parques recreativos y nueve son servicios sanitarios situados en centros comerciales.

Por su parte, en www.gay-cruising.com la lista es más amplia. Se localizaron 46 espacios para cruising en los centros urbanos de las provincias de Heredia, Alajuela, San José y Cartago, de los cuales cuatro son establecimientos particulares (bares, un cine y una sala de video), 13 son parques, calles o jardines de instituciones, mientras que 29 son servicios sanitarios en centros comerciales, universidades, supermercados, almacenes, una estación de tren y un polideportivo. 
Si se comparan estos datos con cifras de estudios realizados en otros países, lucen discretos; no obstante, la visibilidad ${ }^{1}$ de estos lugares suele ser limitada. Así, por ejemplo, en España, para el año 2007, se registraron 31 municipios (de 8104 existentes en ese momento) en los que se anunciaban sitios de interés gay. Estas jurisdicciones contabilizaron un total de 3308 plazas de las cuales, en promedio, el 39\% (4 de cada 10), sin detallar la naturaleza de los encuentros, se especificaron como emplazamientos aptos para prácticas de satisfacción sexual (Fernández-Salinas, 2007).

Es importante mencionar que, en el ámbito local, no abunda la publicación de sitios para consumar el cancaneo, pues es una actividad muy dinámica y con poca exposición al público en general; empero, las páginas citadas constituyen un importante punto de partida para identificar los espacios utilizados para este ejercicio. Como complemento, se buscaron opiniones sobre estos lugares en Internet y, en https://forodecostarica.com, se encontró un chat llamado El Closet con un grupo profuso de expresiones que conforman la fuente testimonial de este trabajo.

En una revisión de los comentarios (todos emitidos por personas con un seudónimo), se observó que los servicios sanitarios públicos son los preferidos para estos encuentros fortuitos. Entre los motivos para su selección está la localización: la mayoría están apartados del tránsito peatonal, ofrecen privacidad y no cuentan con divisiones entre los orinales, aspecto relevante por dos motivos: observar el pene es una de las experiencias más placenteras del cruiser y es en el área de los mingitorios donde, mediante diálogos escuetos o señas corporales convenidas, se hace espontáneamente el contacto que culmina con actos sexuales dentro de los cubículos de los inodoros. Por la seguridad e intimidad que ofrecen dichos recintos, se le ha denominado "oasis eróticos" (Douglas \& Teksbury, 2008, p. 4) y dos cruisers dan testimonio de los beneficios de sus atributos:

...entonces un mae le dijo al otro que se vieran en el 3er piso, en los baños que están en el parqueo, saliendo del cine, esos baños están superrrrrr solos, sin divisiones, nadie va entones se presta mucho para eso... [sic] (carlos25, comunicación personal, 19-12-2013).

1 Víctor Fernández Salinas se basa en Suzanna Danuta Walters para definir el concepto de visibilidad como la normalización del estilo de vida de las personas gais y, para medirla, ha hecho un recuento de la cantidad de menciones de lugares de interés gay que se publican en distintos medios de divulgación (Fernández, 2007). 
...es de las cosas que mas me cuadran, espiar en orinales es un morbo increíble [sic] (Cosbraca, comunicación personal, 24-05-2014).

Además, un aspecto que no se menciona pero que es evidente en los mapas que suministran los sitios web en cuestión, es la céntrica ubicación de los baños en núcleos urbanos de población, la facilidad de acceso, ya sea peatonal o vehicular, y la cercanía a centros de enseñanza superior y oficentros en zonas francas; es decir, en espacios densamente ocupados. Sitios con rasgos semejantes han sido estudiados por Víctor Fernández-Salinas (2007), quien retomó de Wallace Hamilton la noción "escena" para referirse a los emplazamientos urbanos significativos para la comunidad gay y, además, la categorizó en compleja y básica según la cantidad y diversidad de servicios que posibilitan y complementan el encuentro sexual.

La escena, así, constituye un espacio no solo reconocible, sino también accesible; características que se aprecian en la siguiente narración de otro cruiser:

Bueno, ya en Paseo de las flores, aparentemente se acabó la fiesta porque cuando estaba yo en la ulatina me quedaba el mall al puro frente entonces me iba ahí a ver que se veía y los días que iba llegaban maes distintos. [sic] (YoungGhost, comunicación personal 06-12-12).

Varios investigadores afirman que no hay un perfil definido para el cruiser, lo que existe son lugares de cruising que aceptan todo tipo de personas (Dónis-Páez, 2015), aseveración que se puede constatar en las descripciones de los cruisers expuestas en el apartado Tips and Tricks del sitio web www.cruisinggays.com: "estudiantes, gente común, hombres de negocios" son los usuarios del American Outlet Mall, "jóvenes hombres de negocios, trabajadores del mall, turistas" asisten a Multiplaza de Escazú, mientras que, en la Universidad de Costa Rica, hay "todo tipo de chicos, pero especialmente estudiantes y chicos jóvenes".

Un factor preponderante en la práctica del cruising está relacionado con el lenguaje corporal, pues el acercamiento personal entre cruisers requiere de una serie de códigos para identificarse debido a que los encuentros, en gran parte, son indeliberados entre desconocidos. En el chat El Closet, los 
cruisers comparten sus experiencias, entre ellas la forma de identificarse e incitar el encuentro sexual; en términos generales, la relación inicia mediante el contacto visual, los cruisers se ubican en los alrededores de los baños y detectan a otros sujetos interesados, según se infiere en algunos relatos de los usuarios del chat supracitado:

Lo que yo hacía era sentarme fuera de los baños y poner mi gaydar a funcionar jaja esperaba que entrara un mae que yo creía que iba a eso y entraba. [sic] (Younghost, comunicación personal, 06-12-12).

...yo vi como se tocó la entrepierna....Luego el mae se fue al baño, pero me volvió a ver. No sé por qué, pero me fui yo también al baño... [sic] (tony_cr comunicación personal, 23-12-2013).

Dentro los servicios sanitarios las expresiones son más explícitas, así lo describe sincero04:

...la vara es que llega un mae y se pone a mear a la pura par, y me estaba viendo a lo descarado! Uff...Le digo yo, ¿qué es la vara? y me respondió, "mae, qué buen bate..." En ese momento supe que era mi día... [sic] (sincero04, comunicación personal, 22-05-2014).

Tras el intercambio de miradas, el preámbulo sexual continúa con la apreciación del pene en los mingitorios, para finalmente alcanzar el orgasmo. Concluido el acto, cada cruiser continua con su propia agenda, pues lo que prima es lo momentáneo de la reunión y no hay intención de involucrarse (por ello casi no hablan entre sí). Cualquiertipo y tony_cr, participantes del chat El Closet, así lo expresan:

...se vino primero...luego yo. Limpiamos todo, nos despedimos, continué lavándome las manos y salí a clase de nuevo. [sic] (cualquiertipo, comunicación personal, 02-12-2013).

Salimos y nos fuimos. En ningún momento hablé con él, ni supe como se llamaba, ni nada... [sic] (tony_cr, comunicación personal, 23-12-2013). 


\section{EL BAÑO COMO ESPACIO DE SUBVERSIÓN}

El cruising en baños públicos es una práctica que desafía el canon que impone como "normal" la relación heterosexual monógama con fines reproductivos. Es resistencia a una discursividad que universaliza una identidad de género particular $y$, por ello, procede a trastocar una "prótesis de género" que fija una condición de presencia plena (Laclau \& Mouffe, 1987, p.170); es decir, la instauración inalterable de identidades específicas, al resignificar espacios que responden al pensamiento buga.

Apropiarse de los servicios sanitarios es apropiarse de una forma de simbolizar la masculinidad para deconstruirla y reelaborarla y, así, "disolver la especificidad” (Laclau \& Mouffe, 1987, p. 170) que constriñe otras posibles significaciones. El cruiser, el gay, está excluido de un ordenamiento que impone un tipo particular de sexualidad y, por ello, se constituye en un "sujeto flotante", término que Santiago Castro-Gómez (2015) emplea para definir a los condenados de una sociedad que no acogen los preceptos de un grupo hegemónico y, por tanto, se consideran inútiles, anormales, disfuncionales e indeseables (p. 281).

El hombre homosexual, desde esta perspectiva, no cumple con el rol social impuesto que dictamina el cumplimiento de la cópula entre personas de sexo opuesto para la procreación, exigencia devenida del pensamiento judeo-cristiano y que Michel Foucault (1999) interpretó como una acción disciplinar que asegura la reproducción de las poblaciones (p. 247). Es considerado un paria, por ello acoge como estrategia de supervivencia la abyección, condición que David M. Halperin (2007) define como "la tendencia de las poblaciones a identificarse con el juicio social que se levanta contra ellas, al adoptar su propia y supuesta falta de valor y, por tanto, convertir la exclusión social en desafío social” (p. 79).

La supuesta falta de valor del cruiser es la negación de una función reproductiva universalizada y, por este motivo, reta el canon social y se complace en confirmar su homosexualidad mediante el voyerismo y el exhibicionismo, los cuales pueden ser realizados en los servicios sanitarios por las características físicas que presentan: 
En multiplaza escazu los pisos de los baños son muy brillantes y parecen espejos, fácilmente podrías ver lo que te de la gana [sic] (jackcates316, comunicación personal, 27-08-2013).

A mi siempre me a gustado eso del crusing en los baños públicos o el glory hole es súper que bueno, el otro día después de mucho tiempo de no tener experiencias de ese tipo estaba en los baños del Wallmart Curridabat y me dio mucho morbo ver los huecos que hicieron en la pared de yo de ellos, me imagino que hasta sí llegarán maes a buscar este tipo de experiencias... Si conocen algún lugar publiquénlo, a ver que tal y me doy una vuelta. [sic] (claudito, comunicación personal, 29-03-2013).

Pisos relucientes, hoyos o hendijas en las paredes son importantes para la observación del pene; mingitorios sin divisiones son indispensables para exhibirlo; puertas de acceso ruidosas incrementan la adrenalina porque sugieren la posibilidad de ser sorprendidos en el acto sexual:

confieso que el morbo que provoca la posibilidad de que lo pesquen a uno es lo que muchas veces me motiva a hacer varas en lugares públicos. aparte de que me declaro $100 \%$ exhibicionista y me cuadra el voyerismo...algo más??? Jeje [sic] (dispuestoatodo, comunicación personal, 21-09-2012).

La mirada prima para exacerbar el morbo, palabra usada reiteradamente en el argot de los gais y que refleja su abyección. Se define morbo como la atracción a acontecimientos desagradables (DRAE, 2018, s.p.), connotación socialmente aceptada, mas es asumida por los cruisers para expresar su "exaltación perversa" (Halperin, 2007, p. 82), proceso que los conduce a la liberación de su ser, a reconocerse como sujetos con derechos por reivindicar y declarar sus sentimientos sin fijaciones.

Era moreno y de ojos verdes, idílico para mí. Entró al baño mientras me lavaba las manos y lo seguí hasta el cubículo del fondo, nos acomodamos de manera que si alguien se agachaba a ver por la parte baja de la puerta del baño sólo pudiera ver un par de pies. Su cuerpo era el de un joven, su boca la de un angel, sus manos guiaron el ritual hasta lo más sublime de mi primera experiencia. [sic] (cualquiertipo, comunicación personal, 02-05-2013). 
En el testimonio anterior se advierte que el recinto es resignificado: lo que se considera un dispositivo disciplinar de la sexualidad, es el escenario de la consumación de la afectividad gay y, con ello, se trasciende la humillación social (Halperin, 2007, p. 82), la cual consiste en ser señalado y segregado por su transgresión a la norma. También, se neutraliza el poder que genera la persecución social hacia el homosexual (p. 86) quien, de esta forma, se muestra difícil de controlar.

Tal y como lo explica Halperin (2007), el abyecto no se guía por el "régimen de lo normal" ni establece una socialidad convencional, el cruiser tampoco lo hace. Contra las relaciones estables y duraderas de la monogamia heterosexual establece vinculaciones efímeras y anónimas orientadas exclusivamente al placer, germen del triunfo personal (p. 88):

En un baño de Ciencias Sociales de la UCR un día después de un examen de cálculo, del cual salí despigiado, me metí a orinar, la puerta estaba medio cerrada y no me di cuenta que había un mae adentro, le pegué un pichazo con la puerta y el mae me lo agradeció metiéndome al baño y regalándome un par de nalgas que me dejaron bien exprimido. [sic] (cualquiertipo, comunicación personal, 10-06-2013).

El cruising es la confrontación al poder social que procura abrir espacio a otras formas de afectividad humana. Su práctica es un ejercicio de liberación y, por tanto, plantea una reflexión ética orientada a la búsqueda de la libertad individual como una forma de generar el conocimiento propio, aseveración basada en la premisa del "cuidado de sí" de Michel Foucault (1999), la cual se centra en el descubrimiento de uno mismo para dilucidar el significado de la existencia.

A través del "cuidado de sí", el individuo entra en relación consigo mismo, toma consciencia de sus actos y de su sitio con respecto a los demás (Foucault, 1999), de este modo, se reconoce como producto de sus acciones. En este sentido, al saberse gay y al percatarse voyerista, exhibicionista y movedizo, el cruiser se define y hace visible para otros, instituye su Ethos, es decir, "la manera de ser y la manera de conducirse" (Foucault, 1999, p. 263) que le refiere como parte de una comunidad. 
Quien ejerce el cancaneo gay apropiadamente, conoce sus pautas y una de ellas es la identificación de sus practicantes, lo cual amerita la observación de conductas compartidas y descifradas por el grupo. Así lo recalca un cruiser experimentado en un chat con sus compañeros:

Maes yo creo que ustedes no han entendido...el asunto en los baños públicos es una vara casual y fortuita, no un asunto programado... O sea las personas no llegan de 5 a 6 a coger en los baño...no hay horarios. [...] Más que asuntos de horarios es un asunto de actitud y saber observar a los maes que entran a un baño [sic] (cualquiertipo, comunicación personal, 11-06- 2013).

En otra conversación, cualquiertipo señala que "con el tiempo uno se entrena" y así alude a la realización constante de un "cuidado de sí" que asocia la acción con el conocimiento, acto que es parte de una ética que Foucault (1999) concibió como la práctica reflexionada de la libertad, que devela a un sujeto que se sabe devenido de una praxis que está, por demás, impactada por los imperativos impuestos por la sociedad.

Para resistirse y para huir de aquello que le constriñe, el "cuidado de sí" es, entonces, una actividad permanente de libertad que prepara al individuo "para cierta realización completa de la vida" (Giraldo, 2008, p.96) que, dentro del ámbito de la sexualidad, Foucault (1999) vincula con la liberación del deseo para dirimir el comportamiento ético en las relaciones de placer.

La prevalencia de esta libertad es preponderante entre los cruisers, por ello, se reprende a quienes no la han asumido como objetivo supremo. Cualquiertipo, nuevamente, sirve de referente para enseñar esta situación en algunas de sus relaciones:

...se comportaban de una manera muy extraña, como si todos tuvieran cámara sobre sus cabezas con reportes cada 2 minutos a sus familias y amigos. Como muy correctos y perfectos, eso me revienta los huevos... [sic] (comunicación personal, 31-05-2013).

En esta narración se discierne el efecto de las relaciones de poder que limitan al gay, al percibirse el sentimiento de una observancia tácita procedente de reglas de comportamiento que decretan lo decoroso y apropiado. Ante percepciones como esta, opera la resistencia para apartarse 
de anclajes sociales y, por ello, es necesario recurrir al ascetismo, acción recomendada por Halperin (2007) y Foucault (1999), como una forma de subjetivación que conduce a la verdad.

El "cuidado de sí" es un proceso de transformación personal que se torna en una lucha por fraguar una subjetividad propia. Requiere, además del conocimiento propio de lo que se es, del cuestionamiento crítico de las verdades que han sido instauradas políticamente y sujetan al individuo para, de esta manera, participar de los juegos de verdad como un ejercicio de autoformación. Se procede a subjetivar la verdad, es decir, a la creación de una verdad que depende del individuo mismo y no de un poder que le intenta coaccionar para lograr, de esta manera, un nuevo modo de vivir (Fortanet, 2012).

\section{A MODO DE CIERRE}

Tras la interpretación teórica de los documentos examinados, se concluye que el cruising es parte de un proceso de emancipación política de la comunidad gay. Es una praxis de resistencia a la hegemonía buga que, en términos de afectividad, perpetúa la norma heterosexual para clausurar procesos de construcción identitarios divergentes al poder pastoral, término acuñado por Foucault (2006) para referirse a la creación de una gubernamentabilidad basada en la institucionalidad cristiana para alcanzar una meta, y donde el poder se ejerce sobre cada uno de los miembros de una congregación de personas. Desde esta perspectiva, la legislación para la construcción de servicios sanitarios ha sido parte de esa institucionalidad, la cual ha operado de manera soslayada y que amerita ser revisada críticamente para atender, además, las demandas de grupos sexualmente diversos.

En conformidad con la anterior aseveración, también se deduce que el homosexual, individualmente, se constituye en un ser agonal y, colectivamente, conforma una fuerza antagonista, duplicidad que revela la aceptación del conflicto como parte de su vida, pues está intrínseco en el ejercicio perenne para lograr la libertad. El conflicto está relacionado con la condición abyecta que asume para desafiar el orden social que le violenta y para evitar ser una fuerza hegemonizada. En este esfuerzo, el cruiser evade las prácticas discursivas materializadas espacialmente, procura desmantelar preceptos universales y modificar una política que rige para todos; la toma del servicio sanitario así lo revela. 
Entonces, se comprende como política los actos y discursos legitimados socialmente que organizan la convivencia humana y solventan las pugnas (Castro-Gómez, 2015). A partir de este enfoque, el cruiser busca legitimar la naturaleza homosexual del gay y demanda el respeto por una afectividad y una vinculación sexual sin etiquetas, mediante la reapropiación y resemantización de los baños públicos. Estos son lugares que espacializan las prácticas de sí que son concebidas como procesos de liberación, porque conllevan "la acumulación de la fuerza para el fenómeno de la vida" (Castro-Gómez, 2015, p. 230), empoderamiento que implica superar la propia resistencia y abrirse al disfrute del placer sexual.

A este respecto, la arquitectura se muestra como arena política que da cabida a las relaciones de fuerza y, por ello, deja de ser campo de lugares monolíticamente imaginados y se expone como el escenario de antagonismos y procesos de autoconocimiento que procuran salvaguardar la ausencia que evita la sutura simbólica (Laclau \& Mouffe, 1987) y fomentan el agonismo que sostiene al poder, término comprendido como una pluralidad de fuerzas en conflicto; acciones tendientes a evitar los estados de dominación que implantan un fundamento inamovible que, en este caso particular, es la heterosexualidad como canon aprobado para la afectividad.

Finalmente, se observó que la construcción social y física de espacios incide en la instauración y reproducción de hábitos cotidianos del ser humano que afectan su subjetividad. Por esta razón, se han llevado a cabo iniciativas que, de forma coherente, vinculan el discurso con la acción en aras de eliminar fundamentos que segreguen a las personas por su identidad de género. Por ejemplo, en España, durante el gobierno del Partido Socialista Obrero Español, representado por José Luis Rodríguez Zapatero (20042011), se integró la dimensión de género como ámbito a considerar en el diseño de toda normativa gubernamental, con la intención de promover la equidad entre hombres y mujeres y eliminar la segregación. Con esa visión se diseñaron los baños mixtos o de uso familiar en el aeropuerto de Málaga, sitios que no están diferenciados por sexos y son de uso general.

Asimismo, en Costa Rica, desde el 2016 funcionan los denominados baños sin género en la Universidad Latinoamericana de Ciencia y Tecnología (ULACIT) y el Ministerio de Educación Pública, en el 2019, empezó a implementar los baños neutros en centros educativos de primaria y secundaria, con el fin de contrarrestar el bullying a menores de edad provocado 
por la expresión de una orientación sexual y una identidad de género no heteronormada. No obstante, la duda que surge es: ¿reflejan estos actos una sincera aceptación de la diferencia, o son un modo de asumirla para disolverla y debilitarla? Solo el tiempo dirá si se está en presencia de la eliminación de una "prótesis de género" o en una sutil reinvención de la misma.

\section{REFERENCIAS}

Alvarado, J. (5 de abril de 2016). Empresa se disculpa por rótulo ofensivo colocado en baño. CRHoy. Recuperado de https://www.crhoy.com/ archivo/empresa-se-disculpa-por-rotulo-ofensivo-colocado-en-bano/

Castro-Gómez, S. (2015). Revoluciones sin sujeto. Slavoj Zizek y la crítica del historicismo posmoderno. México: Ediciones Akal S.A.

Colegio Federado de Ingenieros y Arquitectos de Costa Rica. (2017). Código de Instalaciones Hidráulicas y Sanitarias en Edificaciones. Recuperado de http://www.pgrweb.go.cr/scij/Busqueda/ Normativa/Normas/nrm_texto_completo.aspx?param1=NRTC\&nValor1=1\&nValor2=83561\&nValor3=107558\&strTipM=TC

Dónis-Páez, F. J. (2015). Geografía, Homosexualidad Masculina y Cruising en Tenerife (Canarias, España). Revista Latino-americana de Geografia e Gênero. 6(2), 173-191. Recuperado de http://salutsexual.sidastudi.org/resources/inmagic-img/DD24397.pdf

Douglas, B. \& Teksbury, R. (2008). Theaters and sex: an examination of anonymous sexualencounters in an erotic oasis. Deviant Behavoir, 29(1), 1-17. doi: 10.1080/08900520701382880

Fernández-Salinas, V. (2007). Visibilidad y escena gay masculina en la ciudad española.Documents d'anàlisi geográfica. (49), 139-160. Recuperado de https://core.ac.uk/download/ pdf/13272343.pdf

Fortanet, J. (2012). Experiencia, ética y poder en la obra de Michel Foucault. Oximora Revista Internacional de Ética y Política. 1, 96-114. Recuperado de http://revistes.ub.edu/index.php/ oximora/article/viewFile/5249/7028 
Foucault, M. (1999). Estética, ética y hermeneútica. Barcelona: Paidós.

Foucault, M. (2006). Seguridad, territorio, población. Recuperado de https://crucecontemporaneo.files.wordpress.com/2012/01/foucault_ michel-seguridad_territorio_poblacion.pdf

Gay Cruising Areas. (s.f.). En Cruising Gays. Recuperado de http://www. cruisinggays.com/Default.aspx?CitylD=2781\&Filter $=4$

Gays-Cruising. (s.f.). Cruising en Costa Rica. Recuperado de https://www. gays-cruising.com/es/costa_rica

Giraldo, R. (2008). La resistencia y la estética de la existencia en Michel Foucault. Entramado, 4(2), 90-100. Recuperado de http://www.redalyc.org/pdf/2654/265420459008.pdf

Grau-Munoz, A., Pla-Ernst, E., Belda-Ibáñez, J., Juan-Corrons, A., Fernández-García, E., Doménech-Alonso, E. ... Alastrue-Loscos, I. (2015). Cruising y e-citas: un nuevo contexto para los encuentros sexuales entre hombres jóvenes que tienen sexo con hombres. Cadernos de saúde pública. 31 (11), 2303-2312. doi: 10.1590/0102-311x00000215.

Halperin, D. (2007). ¿Qué quieren los hombres gay? Sexo, riesgo y vida subjetiva de la homosexualidad. Debate feminista. 36, 273-288. Recuperado de http://www.debatefeminista.pueg.unam.mx/wp-content/ uploads/2016/03/articulos/036_18.pdf

Instituto Nacional de Vivienda y Urbanismo. (1982). Reglamento de Construcciones. Recuperado de http://www.pgrweb.go.cr/scij/Busqueda/ Normativa/Normas/nrm_texto_completo.aspx?param1=NRTC\&nValor1=1\&nValor2=53161\&nValor3=91036\&strTipM=TC

Laclau, E. \& Mouffe, C. (1987). Hegemonía y estrategia socialista. Hacia una radicalización de la democracia. Madrid: Siglo XXI.

Preciado, B. (s.f.). Basura y género. Mear/cagar. Masculino/femenino. Recuperado de https://www.scribd.com/document/196160477/Beatriz-Preciado-Basura-y-genero-Mear-cagar-Masculino-Femenino-doc 
Rojas, L. (2016). Cruising: la apropiación fortuita del espacio público para mantener relaciones sexuales esporádicas entre hombres. Revista Rupturas. 6 (2), 329-344. doi: 10.22458/rr.v6i2.1495

Vigarello, G. (1991). Lo limpio y lo sucio. La higiene del cuerpo desde la Edad Media. Madrid:Alianza Editorial. 